\title{
Effects of Acute Ethanol Administration on Neocortical Inhibition
}

\author{
Lester T. Rutledge, PhD, Shu-Ing Chi, DDS, and Mark A. Sutter, MS
}

\begin{abstract}
The mypothesis that acutely administered ethanol could interfere with neocortical recurrent inhibition (RI) was supported. The large surface negative wave in response to antidromic stimulation of the cerebral peduncle represents a summation of inhibitory postaynaptic potentials, a measure of RI. In acute experiments on adult rats, blood alcohol levels of less than about $120 \mathrm{mg} / 100 \mathrm{ml}$ slightly facilitated the surface negative wave. Higher blood alcohol levels always blocked the surface negative response. Stimulation of the somatosensory thalamic relay nucbei produced a cortical response on which ethanol had a moderate blocking effect. Conditioning-test procedures revealed that cerebral pectuncle stimulation strongty blocked the thalamocortical (test) response, especially after ethanol, but thalamic stimulation (conditioning) had no effect upon the surface negative wave. This demonstrates a differential effect on the two cortical procesess. Cortical Rl seems to be especially sensitive to blood slcohol lovel, but the function of cortical RI is complex. By way of acting on RI, othanol likely affects control of sensory input and cortical sensory organization as well as selectivity and magnitude of motor diecharge.
\end{abstract}

$\mathbf{E}^{\mathrm{T}}$ THANOL is known to affect many areas of the brain. A common assumption, based upon behavioral observations in humans, is that it releases the neocortex from inhibitory control (disinhibition ${ }^{1}$ ). Few neurophysiological data support this assumption, mostly because we know little about possible correlations between commonly measured electrical events, such as evoked potentials and specific cortical functions of excitation and inhibition. For example, an evoked potential recorded from the cortical surface or scalp is a field potential, representing in large part summations of populations of neuronal postsynaptic potentials. Unless the kinds and loci of the postsynaptic potentials are identified, it is not possible to say that a change in evoked potential amplitude under an experimental condition represents more or less excitation or inhibition. To a considerable extent this caution also applies to measures of neuronal unit activity. An extracellular spike can be from either an inhibitory or an excitatory cell.

From the Department of Physiology. The University of Michigan Medical School, Ann Arbor, Michigan.

Received for publication October 14, 1985; revised manuscript received January 21, 1986; accepted March 6, 1986.

This work was supported by Grant 05979 from the National Institute on Alcohol Abuse and Alcoholism.

Reprint requests: Dr. L. T. Rutledge, Department of Physiology, Medical Science Building. The University of Michigan Medical School, Ann Arbor, MI 48109

Copyright $@ 1986$ by The American Medical Society on Alcoholism and The Research Sociely on Alcoholism.
Numerous studies have shown that acutely administered ethanol has mixed or inconsistent effects upon various cortical evoked potentials and neuronal unit firing. ${ }^{2-9}$ More related to the results of our study is the work of Nestoros ${ }^{10,11}$ who found in cat cortex that ethanol potentiated the inhibitory effect of surface stimulation upon neurons as well as $\gamma$-aminobutyric acid-mediated inhibition.

We selected a specific measure of cortical inhibition on which to test the effects of ethanol. The neocortex of mammals contains an inhibitory circuit that includes axon-recurrent collaterals of pyramidal tract and other corticifugal cells synapsing on inhibitory interneurons. ${ }^{12-14}$ Electrical stimulation of the pyramidal tract produces an antidromically mediated complex field potential recorded at the cortical surface. The largest wave of the potential is surface negative (SN) and likely represents a summation of inhibitory postsynaptic potentials. ${ }^{12,15,16}$ The SN wave can be viewed as a measure of one kind of cortical inhibition (recurrent). The functional significance of cortical recurrent inhibition (RI) for motor behavioral expression has been studied. It was found that cortical RI tends to limit the spread of pyramidal tract neuronal activity as well as that of other cortical cells. ${ }^{17}$ As in the spinal cord, ${ }^{18}$ cortical RI appears to have a neuronal discharge frequency-limiting function. ${ }^{17}$ Cortical RI is likely important for controlling a major part of the output from the cortex. The hypothesis for the experiments reported here was that acutely administered ethanol could interfere with a specific cortical inhibitory mechanism, $\mathrm{RI}$, as evaluated by the $\mathrm{SN}$ wave.

\section{METHODS}

\section{Animals}

Data were obtained from experiments on 25 male Sprague-Dawley rats (Charles River) weighing between 410 and $560 \mathrm{~g}$. They had been housed in the animal colony for at least 3 weeks with ad libitum water and standard rat pellet chow. In preliminary experiments it was found that a combination of ketamine $\mathrm{HCl}$ and xylazine gave the most physiologically stable preparations and had no discernible interactive effect with ethanol doses. An initial intramuscular dose of $13 \mathrm{mg} / \mathrm{kg}$ of xylazine was given $10 \mathrm{~min}$ prior to an injection of $90 \mathrm{mg} / \mathrm{kg}$ of ketamine (intraperitoneally). Supplementary doses were: $13 \mathrm{mg} / \mathrm{kg}$ of xylazine every $4 \mathrm{hr}$ and $30-50 \mathrm{mg} / \mathrm{kg}$ of ketamine every $1-1.5 \mathrm{hrs}$. Rats were placed in a stereotaxic apparatus and the dorsal cortical surface exposed under warm mineral oil. Temperatures of the body and the cortical oil pool were maintained by a heating pad and heat lamp. 


\section{Electrodes}

For antidromic stimulation of the motor projection pathway, a concentric bipolar depth electrode was inserted at the level of the cerebral peduncle (CP) where the corticifugal fibers are farthest from the medial lemniscus (rostral, -1.8; lateral, 2.75; depth, 8.75; System B, Pellegrino et al. ${ }^{19}$ ). In larger animals like the cat, antidromic stimulation of corticifugal fibers is best done by isolating the pyramidal tract which prevents stimulating current spread to sensory afferent fibers in the medial lemniscus. ${ }^{20}$ Such isolation is not routinely possible in the small brain of the rat and therefore it was assumed that CP stimulation could lead to some orthodromic effects and activate the somatosensory pathway. For this reason we chose to stimulate the somatosensory thalamic relay area deliberately to produce a thalamocortical (TC) response. This cortical potential could be interacted with the $\mathrm{SN}$ wave in a conditioning-test procedure in order to evaluate contributions of neurons commonly shared in the two pathways activated.

For stimulating and recording from the somatosensory relay in the thalamus, ${ }^{21,22}$ a concentric bipolar electrode was aimed for the ventral nucleus-posterior nucleus complex (rostral, -3.2; lateral, 2; depth, $6.75) .^{19}$ A platinum ball recording electrode was placed on the sensorimotor cortex ${ }^{22.23}$ at the location of best antidromic response to stimulation of the ipsilateral CP. A reference electrode was attached to a screw in the rostral skull. Foot shock was via needles inserted in a foot pad. At the conclusion of each experiment, current was passed through the depth electrodes and loci were determined by histological examination (Weil stain) as necessary.

\section{Blood Alcohol Level}

The procedure for the enzymatic determination of blood ethanol (Sigma Chemcial Co. No. 332-UV) was modified to use small capillary tubes to collect blood samples from the cut end of a rat's tail. Each sample set for blood alcohol level (BAL) measurements was compared with a control standard. In preliminary experiments, BAL data from this procedure were equivalent to those from the Sigma procedure requiring $0.5 \mathrm{ml}$ for each blood sample. It was possible to take blood samples every few minutes without serious blood loss since only about $180 \mu \mathrm{l}$ of blood were needed for each determination. Blood ethanol equilibrates rapidly with brain ${ }^{24}$ and we wanted to observe possible biphasic effects which could start within a few minutes after administration. Ethanol was usually administered in $2 \mathrm{~g} / \mathrm{kg}$ amounts as a $66 \%(\mathrm{v} / \mathrm{v})$ solution in order to keep the volume to about $2 \mathrm{ml}$ since repeated doses would be given in some experiments.

\section{Experimental Procedure}

The response characteristics of the antidromically elicited surface negative wave, the cortical response to thalamic stimulation, the primary cortical potential evoked by foot shock, and the thalamic potential in response to foot shock were established in preliminary experiments. Input-output functions showed that the most reliable response data were obtained by using intensity of stimulation sufficient to produce near maximal responses. Electrical stimulation pulse durations were kept between 0.1 and $0.5 \mathrm{msec}$ and the intensity was varied as necessary but kept constant afier optimal responses were obtained in a particular experiment. For SN elicitation, repetitive shocks were sometimes more effective than single shocks. Standard electrophysiological equipment was used with computer averaging of responses during $50-200$-msec sweeps. The number of sweeps averaged was 5-15 depending upon response variability. Stimulation rate was $1 \mathrm{~Hz}$. Since rate of ethanol uptake varied it was not possible to pool data and therefore individual response curves are presented.

\section{RESULTS}

In preliminary experiments response amplitudes, latencies, and durations were measured but only response amplitudes of the negative waves seemed to vary reliably with BAL and thus this was the exclusive measure. The three principal cortical field potentials are shown in Fig. 1. Note that preceding the SN wave there are one or two positive deflections. These have been identified by others as probably representing pyramidal tract neuron responses (earliest positivity ${ }^{25}$ ) and/or soma or postsynaptic activity (second positivity in cat $^{12}$ ). In only a few preparations could we identify two positive deflections as in Fig. 1B; more usually there was only one as in Fig. 1A. The TC and foot shock evoked potentials consisted of positivenegative components (Fig. 1C). Other succeeding wave components were observed, especially in response to foot shock, but they were too variable for study. Amplitude measurements were made of the major negative wave peaking at 8-10 msec for the SN wave, $10-15 \mathrm{msec}$ for the TC response, and about $15 \mathrm{msec}$ for the potential evoked by foot shock. Since the thalamic response to foot shock was usually small and attenuated, it proved to be of little use in helping to determine if the thalamic-stimulating electrode (central pole for recording) was in the somatosensory relay area.

Ethanol depressed the $\mathrm{SN}$ wave but the effect upon the positive deflection varied (compare Fig. 1A2 and Fig. 1B2). Ethanol at $2 \mathrm{~g} / \mathrm{kg}$ completely eliminated the potential evoked by foot shock within $5-10 \mathrm{~min}$ and there was no, or only slight, recovery after about $1 \mathrm{hr}$ (not illustrated). This effect was in contrast to that seen on the $\mathrm{SN}$ wave and TC responses where negative potential amplitudes were more slowly depressed. Reduction of the SN wave depended upon the rate of ethanol uptake and BAL. Data in Fig. 2 were obtained from two separate experiments. BAL was measured five times during slow uptake after the initial intraperitoneal injection in one of the
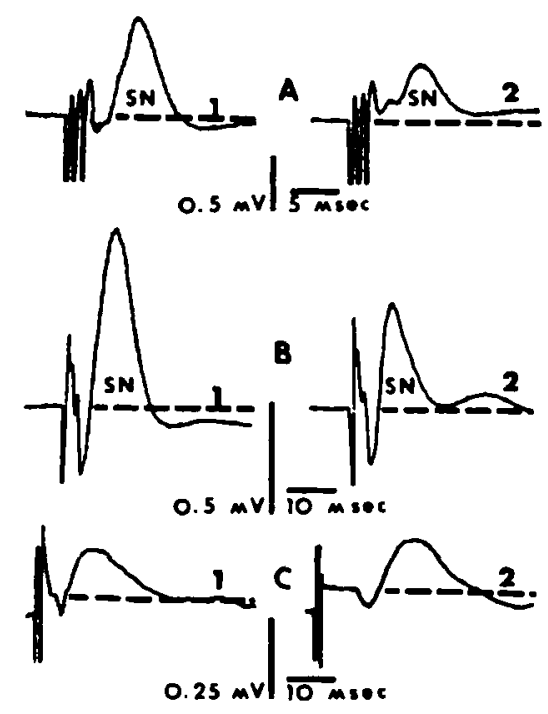

Fig. 1. Cortical surface recordings after stimulation of cerebral peduncle (A, repetitive; $B$, single shock). thalamus (C1), and foot (C2), in animals $A, B$, and $C$. CP stimulation control $S N$ responses are in $A 1$ and $B 1$. A2 is $11 \mathrm{~min}$ after $2 \mathrm{~g} / \mathrm{kg}$ of ethanol (intraperitoneally) and B2, $18 \mathrm{~min}$ after ethanol. Stimulation intensities for just maximal responses. Surface postivity down. Amplitudes measured from the peak of negative potentials to indicated basetine. 


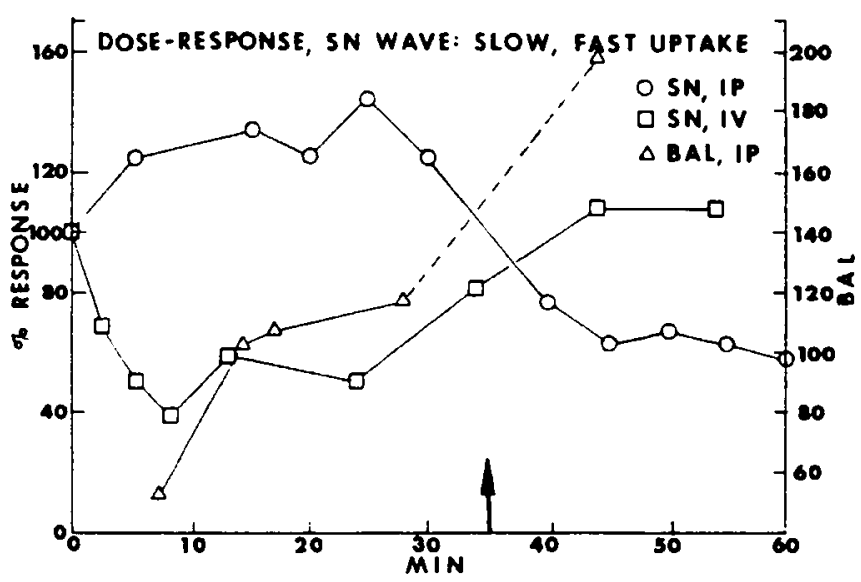

Fig. 2. Effect of ethand on the SN wave. SN wave amplitudes after slow and fast ethand uptake compared in two animals. intraperitoneal administration in one, intravenous in the other. BAL for the intraperitoneal experiment only. Two intraperitoneal injections of $2 \mathrm{~g} / \mathrm{kg}$. the first completed at time zero, the second given at arrow. Intravenous injection, $2 \mathrm{~g} / \mathrm{kg}$ completed at time zero, curation of injection $2 \mathrm{~min}$. Control SN amplitude taken as $100 \%$. BAL in $\mathrm{mg} / 100 \mathrm{ml}$. These are onty "doseresponse" effects in terms of BAL: the curves can be called time-responses.

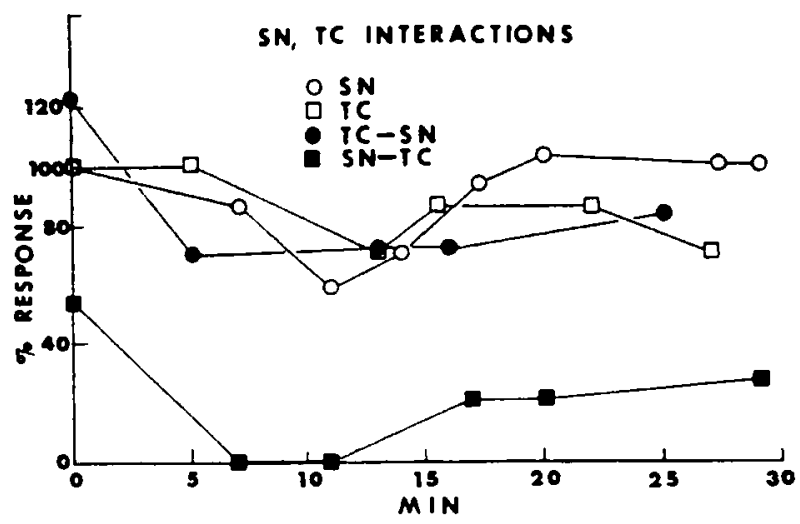

Fig. 3. SN and TC response amplitudes after $2 \mathrm{~g} / \mathrm{kg}$ of ethanol (intraperitoneal) given during $2 \mathrm{~min}$ prior to time zero. Control responses, just prior to ethanol, indicated at zero time. No BAL determinations. SN and TC waves were depressed similarly with maximal effect of about $35 \%$ around $12 \mathrm{~min}$. ., =. conditioning-test interactions, stimultion separation $30 \mathrm{msec}$

animals. A biphasic effect was seen. Below about $120 \mathrm{mg} /$ $100 \mathrm{ml}$ the SN wave amplitude increased, but following a second intraperitoneal injection, $35 \mathrm{~min}$ after the first, there was about a 55\% amplitude decrease while BAL was increasing to $200 \mathrm{mg} / 100 \mathrm{ml}$. Following intravenous injection, where ethanol uptake into brain would be relatively rapid, there was a $50-60 \%$ reduction in $\mathrm{SN}$ wave amplitude for about $25 \mathrm{~min}$ following which the SN wave "recovered." Such recovery was frequently seen in about $1 \mathrm{hr}$ after a single intraperitoneal injection when the BAL had begun to fall toward $120 \mathrm{mg} / 100 \mathrm{ml}$. In some experiments there was an indication that "tolerance" could develop since amplitude of the $\mathrm{SN}$ wave showed an increase from its smallest point before the BAL began to decrease.

In an experiment in which BAL was not determined, ethanol seemed to have an equal effect upon TC and SN responses (Fig. 3). However, when the responses were interacted, reciprocal blocking effects were not found.
Prior to ethanol administration, thalamic stimulation seemed to facilitate the SN wave about $20 \%$ (TC-SN, Fig. 3 ), but this is an artifact since it could be explained by this unusual TC response's long duration (more than $30 \mathrm{msec}$ ) which algebraically summated with the $\mathrm{SN}$ wave. In all experiments where the thalamic electrode was correctly located in somatosensory relay structures, thalamic conditioning stimulation had no significant effect upon the SN wave (Fig. 4). The weak effect of thalamic stimulation (conditioning) upon the SN wave (test) was totally different from that seen when CP stimulation preceded that to the thalamus. Prior to ethanol, CP stimulation reduced the TC response by about 50\%; after ethanol, it blocked it completely from about 7-11 min (Fig. 3).

Figs. 4 and 5 show the relationships between the effects of a single ethanol dose and electrophysiological responses

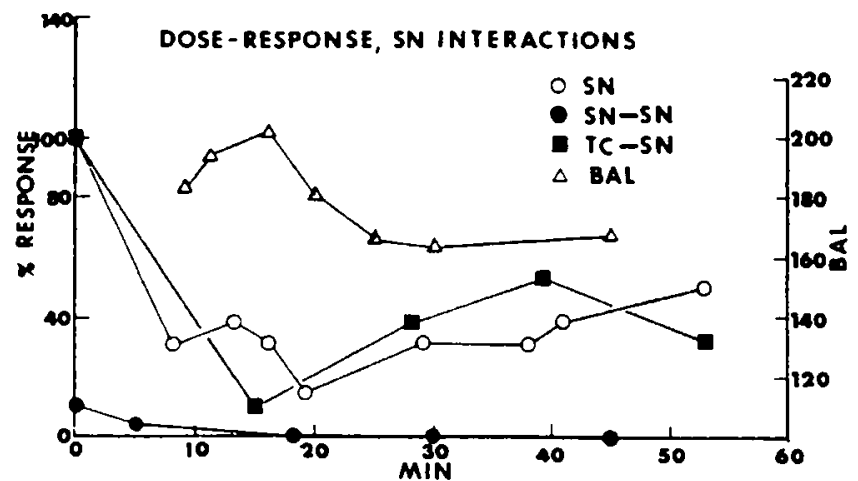

Fig. 4. BAL and SN wave amplitudes after a single intraperitoneal injection of 2 g/kg during $2 \min$ prior to time zero. Control SN amplitude taken as $100 \%$. Rapid block of SN wave occurred with BAL rising above $180 \mathrm{mg} / 100 \mathrm{ml}$ within $8 \mathrm{~min}$. The SN wave started to recover slightly by 50 min even though BAL leveled of around $165 \mathrm{mg} / 100 \mathrm{mt}$. Dual shocks to $C P$ (SN-SN), separated by $110 \mathrm{msec}$, resulted in $90 \%$ SN wave block prior to ethanol and total block after. Thalamic stimulation (TC) preceding CP stimulation (SN) by 50 msec had no additional effect upon the SN wave. Dose-response: see Fig. 2.

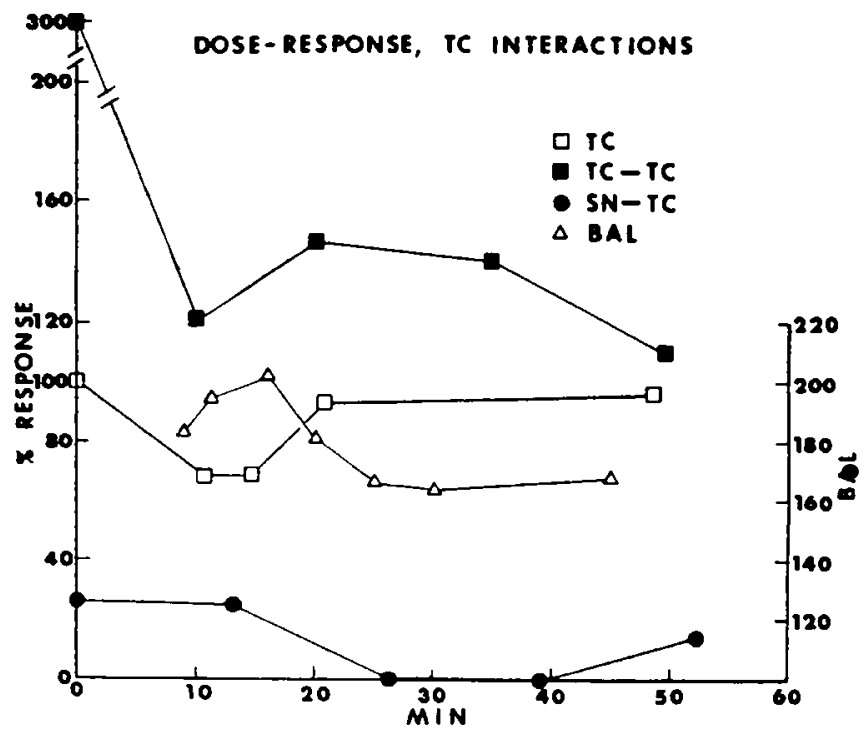

Fig. 5. Same experiment as in Fig. 4, but TC response emphasized. TC response decreased $32 \% 11 \mathrm{~min}$ after $2 \mathrm{~g} / \mathrm{kg}$ of ethanol (intraperitoneal). However, TC response was greatly facititated when dual thalemic shocks spaced $110 \mathrm{msec}$ were given. Conditioning stimulation to CP preceding thalamic stimulation by $110 \mathrm{msec}$ totaly blocked the TC response by $26 \mathrm{~min}$. Doseresponse: see Fig. 2 . 
obtained during seven BAL determinations made over the same time period. Fig. 4 clearly shows the usual observation of SN wave blockade by BAL above $160 \mathrm{mg} / 100 \mathrm{ml}$ and that activation of the TC pathway with a conditioning shock had no additional effect upon the $\mathrm{SN}$ wave. Note the total refractoriness of the SN wave, after ethanol, when dual shocks to $C P$ were given. In Fig. 5 two other consistent findings are illustrated. First, in nine experiments where histology verified the thalamic-stimulating location as being in or near the posterior nucleus, the ventral nucleus, or the medial lemniscus, $2 \mathrm{~g} / \mathrm{kg}$ of ethanol reduced the TC response amplitude an average of $45 \%$ within 11-25 min. Second, in contrast to the absence of TC effect upon the $\mathrm{SN}$ wave, stimulation of $\mathrm{CP}$ reduced the TC response to zero by $26 \mathrm{~min}$. There were no exceptions to this nonreciprocal blocking relationship between $\mathrm{TC}$ and $\mathrm{SN}$ responses (Figs. 3, 4, and 5). In the majority of experiments, ethanol had a greater blocking effect upon the SN wave than it did upon the TC response. Also of note, in contrast to $\mathrm{SN}$ refractoriness with dual CP shocks (Fig. 4), dual stimulation of the thalamus resulted in facilitation of the TC response (Fig. 5).

\section{DISCUSSION}

The hypothesis for these experiments was supported by finding a consistent relationship between BAL above about $120 \mathrm{mg} / 100 \mathrm{ml}$ and the amplitude of a negative cortical potential which is a measure of recurrent inhibition. BAL below above $120 \mathrm{mg} / 100 \mathrm{ml}$ occasionally slightly facilitated the antidromically elicited $\mathrm{SN}$ wave, but always blocked it at higher BALs. This biphasic effect has been described for other ethanol effects on the brain. ${ }^{26}$ The other cortical responses evoked by foot shock and thalamic relay stimulation also responded to ethanol. The potential evoked by foot shock was quickly blocked and showed little recovery, while the TC response could be reduced about $45 \%$ with marked recovery of tolerance even though BALs were not dropping. This apparent tolerance was also observed with the $\mathrm{SN}$ wave, but less frequently. Conditioning-test pairings revealed that ethanol had different effects on the two cortical systems, as represented by the TC response and the $\mathrm{SN}$ wave.

$\mathrm{CP}$ stimulation (conditioning) producing the $\mathrm{SN}$ wave, strongly blocked the TC response (test), and even more so after ethanol. The reverse, TC block of the $\mathrm{SN}$ wave, was not found. These differential effects can be explained by assuming two different cortical circuits are involved. It has already been pointed out that the $\mathrm{SN}$ wave likely represents summations of synchronous inhibitory postsynaptic potentials in a recurrent inhibitory circuit. ${ }^{12.15}$ The basis for the TC response is much less definite. Cortical surface potentials are field potentials, reflections of summations of synchronized postsynaptic potentials and fiber activity rather than neuronal action potentials. ${ }^{15,27,28}$ It is theoretically possible to identify the loci of inhibitory and evoked postsynaptic potential generators associated with evoked field potentials and to draw conclusions about which components of an evoked potential represent excitation or inhibition. However, as pointed out by Humphrey ${ }^{15}$ and Towe, ${ }^{28}$ experimental results are exceedingly difficult to obtain. Creutzfeldt et al. ${ }^{29}$ in experiments on cats, showed that the large, early surface negativity in response to stimulation of the ventral-lateral nucleus of the thalamus, represents both excitatory and inhibitory postsynaptic potential activity at different locations on neurons in upper cortical layers (vertically elongated pyramidal cells). The TC negative wave, in our experiments, is likely a mixture of synchronized depolarizations in apical dendrites of pyramidal cells below the recording electrode and hyperpolarizations in the region of their somas. In the cat, Towe $^{28}$ implicated pyramidal cells in layers II and III as receiving somatosensory input from the thalamus. In our experiments, ethanol depressed the TC negative wave by $45 \%$, but there is no way of proving whether the block was on deep hyperpolarizations (block of inhibition) or on superficial depolarizations (block of excitation). However, since ethanol also depressed the $\mathrm{SN}$ wave (above a BAL of $120 \mathrm{mg} / 100 \mathrm{ml}$ ) it is suggested that ethanol has only one kind of action on the TC and SN responses, a block of postsynaptic inhibition. That two different neural circuits are involved in mediating the $\mathrm{SN}$ wave and $\mathrm{TC}$ response is also supported by the observations that dual shock produced inhibition of the $\mathrm{SN}$ wave and facilitation of the TC response.

Our observations and interpretations are based upon the use of ketamine-xylazine for anesthesia. Although we did note that $\mathrm{SN}$ wave depression after ethanol occurred without dependence upon the depth of anesthesia, the observations on the $\mathrm{SN}$ wave should be confirmed in other species and under different conditions, such as, without general anesthesia. The present data on ethanol block of the TC response and the potential evoked by foot shock do confirm similar studies by others on evoked potentials with and without anesthesia.

Story et al. ${ }^{30}$ found that $2 \mathrm{~g} / \mathrm{kg}$ of ethanol, in unanesthetized cats, blocked the large cortical negative wave (peak at about $10 \mathrm{msec}$ latency) to thalamic sensory relay stimulation and the visual cortex response (not illustrated) to optic tract stimulation. Perrin et al. ${ }^{4}$ observed that ethanol blocked the early (within about $25 \mathrm{msec}$ ) complex auditory-evoked cortical response in unanesthetized cats, but only if BAL reached about $50 \mathrm{mg} / 100 \mathrm{ml}$. Hetzler et al. ${ }^{31,32}$ studied positive and negative cortical potentials during about $300 \mathrm{msec}$, in response to photic stimulation, in unanesthetized rats. Late and early waves were depressed but one positive wave was enhanced by ethanol $(1.0-2.5 \mathrm{~g} / \mathrm{kg})$. BAL was not given. From a review of many studies $^{26}$ it is obvious that ethanol has multiple loci of effects in the brain; some of these are in the neocortex.

The previous reports of ethanol effects on evoked neocortical potentials have not considered the neuronal bases 
for the observations. One does not know whether ethanol affected processes of excitation or inhibition in those experiments and thus conclusions about function cannot be made. As a result of relating the evoked TC response to the SN wave in the present experiments, it can be suggested that two different circuits were affected by ethanol in different degrees, both circuits contained some shared inhibitory interneurons, and the interaction between activity in the circuits was in one direction only. It may be concluded that acutely administered ethanol above about $120 \mathrm{mg} / 100 \mathrm{ml}$ blocks neocortical inhibitory processes and this occurs via inhibitory interneurons. If BAL is low and rises slowly toward $120 \mathrm{mg} / 100 \mathrm{ml}$, an initial effect may be a slightly increased amount of recurrent inhibition, but since ethanol infrequently increased the SN wave amplitude we tend to discount this observation.

Low doses of ethanol caused neocortical desynchronization and high doses synchronization and delta waves. ${ }^{26}$ These effects have been interpreted as evidence for cortical excitation and inhibition on the afferent side. Low doses of ethanol increased spontaneous locomotor activity and high doses inhibited $\mathrm{it}^{33}$; these are efferent effects. We view ethanol block of neocortical RI as one effect which could lead to increased motor discharge from the cortex. Although the function of RI in the cortex is unknown it may act to limit the frequency and the selectivity of discharge from cortical motor cells, analogous to its possible function in the spinal cord. ${ }^{34}$ Another effect of ethanol may be upon other inhibitory neurons ${ }^{35}$ which normally fine tune smaller cortical regions and circuits. The total effect could be a loss of selectivity of cortical motor control and an increased excitation of lower motor neurons. Although in the following paper, ${ }^{36}$ we suggest that chronic ethanol treatment results in loss of inhibition upon cortical excitatory processes, it seems too restrictive to explain the effect of acute ethanol upon the cerebral cortex as "disinhibition." Ethanol blocks RI in the hippocampus, ${ }^{37}$ a nonmotor structure. It is likely that RI in both hippocampus and neocortex may also function to control the proper distribution of neuronal activity initiated by afferent input. ${ }^{36}$

\section{ACKNOWLEDGMENT}

Thanks are extended to John P. Willie for technical assistance.

\section{REFERENCES}

1. Woods SC, Mansfield JG: Ethanol and disinhibition: Physiological and behavioral links. in Room M, Collins G (eds): Alcohol and Disinhibition: Nature and Meaning of the Link. Research Monograph 12, United States Department of Health and Human Services. Washington DC, Government Printing Office, 1983

2. Lake N, Yarbrough GG, Phillis JW: Effects of ethanol on cerebral cortex neurons: Interactions with some putative transmitters. J Pharm Pharmacol 25:582-584, 1973

3. Salamy A, Williams HL: The effects of alcohol on sensory evoked and spontaneous cerebral potentials in man. Electroencephalogr Clin Neurophysiol 35:3-11, 1973
4. Perrin RG, Hockman $\mathrm{CH}$, Kalant $\mathrm{H}$, Livingston $\mathrm{KE}$ : Acute effects of ethanol on spontaneous and auditory evoked electrical activity on cat brain. Electroencephalogr Clin Neurophysiol 45:19-31, 1974

5. Wayner MJ, Ono T, Nolley D: Effects of ethyl alcohol on central neurons. Pharmacol Biochem Behav 3:499-506, 1975

6. Klemm WR, Mallari CG, Dreyfus LR, Fiske JC, Forney E, Mikeska JA: Ethanol-induced regional and dose-response differences in multiple-unit activity in rabbits. Psychopharmacology 49:235 244, 1976

7. Hyvärinen JL, Laakso M, Roine R, Leinonen L: Comparison of effects of phenobarbital and ethanol on the neuronal activity in posterior parietal association cortex. Acta Physiol Scand 107:219-225, 1979

8. Sutko MH, Weinberger NM: Effects of ethanol on the cochlear nucleus and auditory cortex in the cat. J Stud Alcohol 40:799-822, 1979

9. Collins JG, Roppolo JR: Effects of pentobarbital and ethanol upon single-neuron activity in primary somatosensory cortex of the rhesus monkey. J Pharmacol Exp Ther 213:337-345, 1980

10. Nestoros JN: Ethanol specifically potentiates GABA-mediated neurotransmission in feline cerebral cortex. Science 209:708-710, 1980

11. Nestoros JN: Ethanol selectively potentiates GABA-mediated inhibition of single feline cortical neurons. Life Sci 26:519-523, 1980

12. Humphrey DR: Re-analysis of the antidromic cortical response. I. Potentials evoked by stimulation of the isolated pyramidal tract. Electroencephalogr Clin Neurophysiol 24:116-129, 1968

13. Phillips CG: Actions of antidromic pyramidal volleys on single Betz cells in the cat. Q J Exp Physiol 44:1-25, 1959

14. Renaud LP, Kelly JS: Simultaneous recordings from pericruciate pyramidal tract and non-pyramidal tract neurons; response to stimulation of inhibitory pathways. Brain Res 79:29-44, 1974

15. Humphrey DR: Re-analysis of the antidromic cortical response. II. On the contribution of cell discharge and PSPs to the evoked potentials. Electroencephalogr Clin Neurophysiol 25:421-442, 1968

16. Anderson TE, Rutledge LR: Inhibition in penicillin-induced epileptic foci. Electroencephalogr Clin Neurophysiol 46:498-509, 1979

17. Kameda K, Nagel R, Brooks VB: Some quantitative aspects of pyramidal collateral inhibition. J Neurophysiol 32:540-553, 1969

18. Granit R, Haase J, Rutledge LT: Recurrent inhibition in relation to frequency of firing and limitation of discharge rate of extensor motoneurons. J Physiol (Lond) 154:308-328, 1960

19. Pellegrino LJ, Pellegrino AS, Cushman AJ: A Stereotaxic Atlas of the Rat Brain, 2nd ed. New York, Plenum, 1979

20. Chen $Z$, Towe AL: Cerebral response to medullary pyramid stimulation in the rabbit. Brain Behav Evol 25:175-186, 1984

21. Knook HL: The Fibre-connections of the Forebrain. Philadelphia, Davis, 1965

22. Herkenheim M: Laminar organization of thalamic projections to the rat neocortex. Science 207:532-535, 1980

23. Woolsey CN: Organization of somatic sensory and motor areas of the cerebral contex, in Harlow HF, Woolsey CN (eds): Biological and Biochemical Bases of Behavior. Madison, Univ Wisconsin, 1958, pp 6381

24. Sunahara GI, Kalant H, Schofield M, Grupp L: Regional distribution of ethanol in rat brain. Can J Physiol Pharmacol 56:988-992, 1978

25. Harrison TA, Towe AL: Responses of rat cerebral cortex to medullary pyramidal tract stimulation. Soc Neurosci Abstr 8:540, 1982

26. Kalant $H$, Woo N: Electrophysiological effects of ethanol on the nervous system. Pharamcol Ther 14:431-457, 1981

27. Purpura DP: Nature of electrocortical potentials and synaptic organizations in cerebral and cerebellar cortex. Int Rev Neurobiol 1:47163,1959

28. Towe AL: On the nature of the primary evoked response. Exp Neurol 15:113-139, 1966

29. Creutzfeldt OD, Watanabe S, Lux HD: Relations between EEG phenomena and potentials of single cortical cells. I. Evoked responses after thalamic and epicortical stimulation. Electroencephalogr Clin Neurophysiol 20:1-18, 1966 
30. Story JL, Eidelberg E, French JD: Electrographic changes induced in cats by ethanol intoxication. Arch Neurol 5:119-124, 1961

31. Hetzler BE, Heilbronner RL, Griffin J, Griffin G: Acute effects of alcohol on evoked potentials in visual cortex and superior colliculus of the rat. Electroencephalogr Clin Neurophysiol 51:69-79, 1981

32. Hetzler BE, Oaklay KE, Heilbronner RL, Vestal T: Acute effects of alcohol on photic evoked potentials of albino rats: Visual cortex and superior colliculus. Pharmacol Biochem Behav 17:1313-1316, 1982

33. Matchett JA, Erickson CK: Alteration of ethanol-induced changes in locomotor activity by adrenergic blockers in mice. Psychopharmacology 52:201-206, 1977
34. Granit R, Rutledge LT: Surplus excitation in reflex action of motoneurons as measured by recurrent inhibition. J Physiol (Lond) 154:288-307, 1960

35. Houser CR, Vaughn JE, Hendry SHC, Jones EG, Peters A: GABA neurons in the cerebral cortex, in Jones EG, Peters A (eds): Cerebral Cortex, vol 2. New York, Plenum, 1984, pp 63-89

36. Rutledge LT, Sutter MA, Chi S-I, Gray TA: Effects of chronic ethanol treatment on neocortex. Alcohol Clin Exp Res 10:512-516, 1986

37. Abraham WC, Hunter BE, Zornetzer SF, Walker DW: Augmentation of short-term plasticity in CAl of rat hippocampus after chronic ethanol treatment. Brain Res 221:271-287, 1981 